\title{
AN UNUSUAL PRESENTATION OF ENDOMETRIAL CARCINOMA: A CASE REPORT
}

Sabuj Baran Biswas ${ }^{1}$

\section{HOW TO CITE THIS ARTICLE:}

Sabuj Baran Biswas. "An Unusual Presentation of Endometrial Carcinoma: A Case Report". Journal of Evolution of Medical and Dental Sciences 2015; Vol. 4, Issue 62, August 03; Page: 10864-10868,

DOI: $10.14260 /$ jemds/2015/1568

ABSTRACT: A 70years female of P2L2, presented with chief complaints of postmenopausal bleeding associated with pain lower abdomen for last 10 days. She attained menopause 15 years back with past h/o irregular menstrual cycles. She was known hypertensive on treatment. General examination revealed mild pallor, BP-140/90mmHg with no regional lymphadenopathy. Abdomen was soft, nontender. Per speculum examination revealed a polyp coming through the cervical os. Bleeding through os was present. Per vaginal examination showed normal sized, anteverted, firm, mobile, nontender uterus with free fornices. Pap smear revealed inflammatory smear without evidence of malignancy. USG of Abdomen \& pelvis showed uterus $(8.1 \times 6.4 \times 5.4) \mathrm{cm}$ with normal myometrial, endometrial echoes, endometrial thickness of $5 \mathrm{~mm}$ with minimal ascites. Polypectomy \& Fractional Curettage were done. Histopathology report showed Endometrial Adenocarcinoma (Grade 2). Staging laparotomy (Extrafascial Hysterectomy with Bilateral Salpingo-oophorectomy) with pelvic and paraaortic lymphadenectomy and omentectomy were done. Patient developed hypertension in the immediate postoperative period which was controlled by nitroglycerine. Histopathology revealed villoglandular type of endometrioid carcinoma with metastatic deposits in ovaries and omentum, not involving lymphnodes. The patient was diagnosed as a case of Stage IV Carcinoma Endometrium. Combination chemotherapy with doxorubicin \& cisplatin was started and she is now under follow up.

INTRODUCTION: Endometrial cancer is the fourth leading cancer in incidence but only the eighth leading cause of cancer deaths among women. ${ }^{1}$ The average age at diagnosis is the early $60 \mathrm{s.}{ }^{2,3}$

Obesity is the most common cause of endogenous overproduction of estrogen. Unopposed estrogen therapy is the next most important potential inciting factor. Fortunately, the malignant potential of continuous or sequentially administered estrogen was recognized more than three decades ago. ${ }^{4}$ Currently, it is rare to encounter a woman with a uterus who has been on unopposed estrogen for years. Instead, combined estrogen plus progestin hormonal therapy is prescribed routinely for postmenopausal women with a uterus to reduce their risk of endometrial cancer. ${ }^{4}$ There remain questions about how effective this combination strategy is at preventing endometrial cancer, but certainly it is superior to unopposed estrogen. ${ }^{5}$

Polycystic ovary syndrome (PCOS), which also causes irregular or no ovulation, is associated with higher rates of endometrial cancer. ${ }^{6}$ Lynch syndrome, an autosomal dominant genetic disorder that mainly causes colorectal cancer, also causes endometrial cancer, especially before menopause.

Carcinogenesis in Lynch syndrome comes from a mutation in MLH1 and/or MLH2: genes that participate in the process of mismatch repair, which allows a cell to correct mistakes in the DNA. ${ }^{6}$

There is an increased incidence of p53 overexpression among African American women as compared with white women. ${ }^{7}$

Abnormal uterine bleeding is the most common presenting symptom of endometrial cancer. 


\section{CASE REPORT}

In a review of the pathological findings among women with postmenopausal bleeding, it was found that the risk of adenomatous endometrial hyperplasia or cancer in a woman with postmenopausal bleeding is approximately $18 \%{ }^{8}$

A cervical screening test, such as a Pap smear, is not a useful diagnostic tool for endometrial cancer because the smear will be normal $50 \%$ of the time. ${ }^{9}$ Transvaginal pelvic ultrasonography should be the first step in the evaluation of postmenopausal bleeding, with an endometrial stripe thickness of less than $4 \mathrm{~mm}$ being defined as normal. Office endometrial biopsy is recommended for those patients with an endometrial stripe thickness of less than $4 \mathrm{~mm}$ who were at high risk of endometrial cancer or who had persistent bleeding and for all patients with endometrial stripe thickness greater than or equal to $4 \mathrm{~mm} .10$

CASE REPORT: A 70 years Hindu female of lower-middle socioeconomic status, P2L2, presented with chief complaints of postmenopausal bleeding associated with pain lower abdomen for last 10 days. She attained menopause 15 years back with past history of irregular menstrual cycles. She was known hypertensive on treatment for last 1 year with no significant past and family history of breast, ovary and colon malignancies.

General examination revealed mild pallor, BP-140/90mmHg with no regional lymphadenopathy. She was of average built with BMI of $32 \mathrm{~kg} / \mathrm{m}^{2}$. Systemic examination was within normal limits. Abdomen was soft, non- tender. Per speculum examination revealed a polyp coming through the cervical os. Bleeding through os was present. Per vaginal examination showed normal sized, anteverted, firm, mobile, nontender uterus with free fornices. Treatment was started with trenaxamic acid, ofloxacin, and metronidazole.

Pre-operative investigations were within normal limits. Pap smear revealed inflammatory smear with no evidence of malignancy.

Ultrasonography of abdomen \& pelvis showed uterus $(8.1 \times 6.4 \times 5.4) \mathrm{cm}$ with normal myometrial, endometrial echoes, endometrial thickness of $5 \mathrm{~mm}$ with minimal ascites in peritoneal cavity. Cervix \& cervical canal were normal. Ovaries were not visible.

Polypectomy \& Fractional Curettage were done. A (2x2) cm polyp was removed. Uterocervical length was $7 \mathrm{~cm}$. Profuse amount of endometrium was curetted out. Polyp \& Endometrial samples were sent for histopathological study.

Histopathology report showed small clusters of endometrial glands with cells having hyperchromatic nuclei on a background of extensive necrosis \& inflammatory infiltrate. Impression was endometrial sample suggestive of Endometrial Adenocarcinoma (Grade 2).

After pre-anaesthetic \& cardiological evaluation patient was planned for surgery.

Staging laparotomy (Extrafascial Hysterectomy with Bilateral Salpingo-oophorectomy) was done. Pelvic lymphadenectomy (right and left upper \& lower external illiac, common illiac, internal illiac, obturator nodes), paraaortic lymphadenectomy and omentectomy were done. There was moderate amount of ascitic fluid in pouch of doughlas, right \& left paracolic gutter and subdiaphragmatic area. Vault closure was done. Specimens of ascitic fluid, uterus with appendages, lymphnodes, omentum were sent for histopathological study and biopsy. Patient developed hypertension in the immediate postoperative period which was controlled by nitroglycerine. Postoperative period was uneventful.

On gross section, uterus $(9 \times 6 \times 5) \mathrm{cm}$ and cervix appeared healthy. On cut section, (Image-1) uterine cavity showed endometrial hyperplasia. A growth $(6 \times 4) \mathrm{cm}$ was found inside the endometrial 
cavity. Endocervical canal was normal. Right ovary appeared grossly abnormal. A $1.5 \mathrm{~cm}$ diameter cyst was found on left ovary. Nodular areas were found over omentum.

Histopathology revealed (Image-2) villoglandular type of endometrioid carcinoma with metastatic deposits in ovaries and omentum (Image-3), not involving lymphnodes associated with chronic cervicitis.

So, finally the patient was diagnosed to be a case of Stage IV Carcinoma Endometrium. As per advice of the Medical Oncologist, combination chemotherapy with doxorubicin \& cisplatin was started and she is now under follow up.

DISCUSSION: Treatment of Stage IV disease is patient dependent but usually involves a combination of surgery, radiation therapy, and systemic chemotherapy or hormonal therapy. History and physical examination remain the most effective methods of follow-up in patients treated for endometrial cancer.

Fortunately, patients typically seek medical attention early due to vaginal bleeding, and endometrial biopsy leads quickly to diagnosis. The primary treatment is hysterectomy with bilateral salpingo-oophorectomy (BSO) and lymphadenectomy for most women. Three quarters of patients will have stage I disease that is curable by surgery alone. Patients with more advanced disease typically require postoperative combination chemotherapy, radiotherapy, or both.

The role of surgical lymphadenectomy has been continuously debated since the FIGO staging criteria were adopted. Assessment of the lymph node-bearing tissue has been interpreted by some to include lymph node inspection and/or palpation with selective biopsies of suspicious areas. Data suggest that this technique is of limited value as microscopic metastases can be frequently missed by inspection/palpation. ${ }^{11}$

Most surgically treated patients simply can be followed by pelvic examination every 3 to 4 months for the first 2 years and twice yearly for an additional 3 years before returning to annual visits. ${ }^{12}$ Women who have more advanced disease that requires postoperative radiation or chemotherapy or both warrant more aggressive monitoring. In general, the pattern of recurrent disease depends on the original sites of metastasis as well as the treatment received.

Paclitaxel (Taxol), doxorubicin (Adriamycin) and cisplatin (TAP) chemotherapy is the adjuvant treatment of choice for advanced endometrial cancer. In a randomized phase III GOG trial of 273 women (protocol 177), administration of seven courses of TAP was superior to doxorubicin and cisplatin (AP), but toxicity was increased-particularly peripheral neuropathy. ${ }^{13}$

In practice, cytotoxic chemotherapy frequently is combined with radiotherapy in patients with advanced endometrial cancer. To reduce toxicity, directed pelvic or para-aortic radiation usually is employed rather than whole abdominal irradiation. 


\section{CASE REPORT}

Image 1: Cut section of uterus with growth inside endometrial cavity.

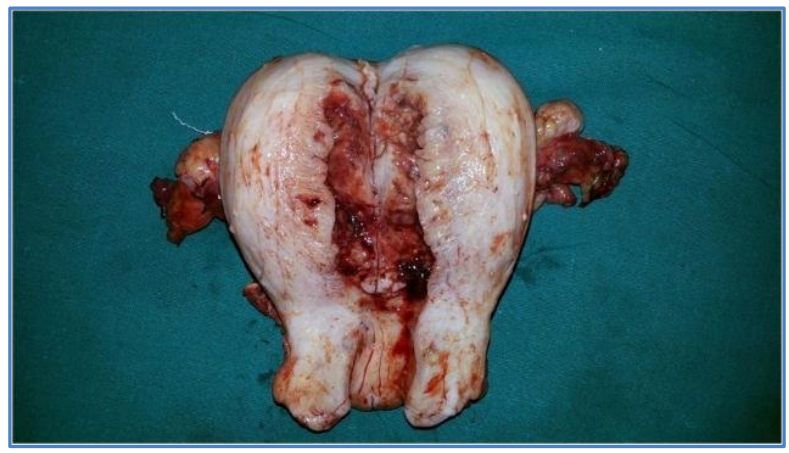

Fig. 1

Image 2: Histopathological picture showing Endometrium- endometrioid carcinoma (Papillary villoglandular architecture).

Image 3: Histopathological picture showing metastatic deposits in omentum.

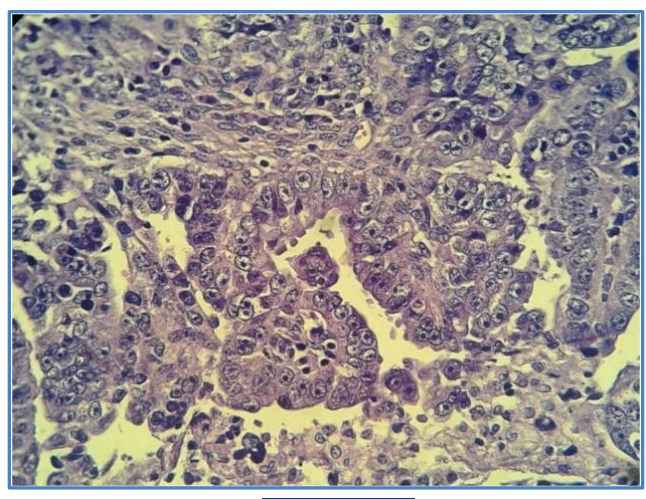

Fig. 2

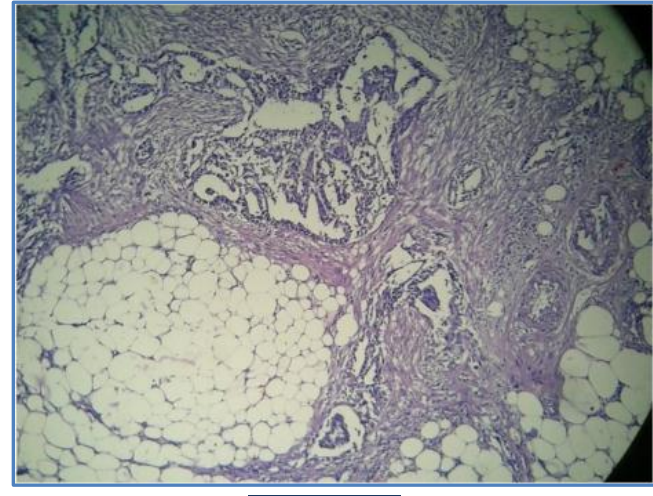

Fig. 3

\section{REFERENCES:}

1. Jemal A, Siegel R, Ward E, et al: Cancer statistics, 2007. CA Cancer J Clin 57(1):43, 2007 [PMID: 17237035].

2. Farley JH, Nycum LR, Birrer MJ, et al: Age-specific survival of women with endometrioid adenocarcinoma of the uterus. Gynecol Oncol 79:86, 2000 [PMID: 11006037].

3. Madison T, Schottenfeld D, James SA, et al: Endometrial cancer: Socioeconomic status and racial/ethnic differences in stage at diagnosis, treatment, and survival. Am J Public Health 94:2104, 2004 [PMID: 15569961].

4. Smith DC, Prentice R, Thompson DJ, et al: Association of exogenous estrogen and endometrial carcinoma. N Engl J Med 293:1164, 1975 [PMID: 1186789]

5. Lacey JV Jr, Brinton LA, Lubin JH, et al: Endometrial carcinoma risks among menopausal estrogen plus progestin and unopposed estrogen users in a cohort of postmenopausal women. Cancer Epidemiol Biomark Prev 14:1724, 2005 [PMID: 16030108].

6. Hoffman, BL; Schorge, JO; Schaffer, JI; Halvorson, LM; Bradshaw, KD; Cunningham, FG, eds. (2012). "Endometrial Cancer". Williams Gynecology (2nd ed.).McGraw-Hill. p. 818. ISBN 978-007-171672-7. 


\section{CASE REPORT}

7. Schimp VL, Ali-Fehmi R, Soloman LA, et al. The racial disparity in outcomes in endometrial cancer: could this be explained on a molecular level? Gynecol Oncol 2006; 102: 440.

8. Gredmark T, Kvint S, Havel G, et al. Histopathological findings in women with postmenopausal bleeding. BJOG 1995; 102: 133.

9. Hoffman, BL; Schorge, JO; Schaffer, JI; Halvorson, LM; Bradshaw, KD; Cunningham, FG, eds. (2012). "Endometrial Cancer". Williams Gynecology (2nd ed.).McGraw-Hill. p. 823. ISBN 978-007-171672-7.

10. Moodley M, Roberts C. Clinical pathway for the evaluation of postmenopausal bleeding with an emphasis on endometrial cancer detection. J Obstet Gynnaecol 2004; 24: 736.

11. Arango HA, Hoffman MS, Roberts WS, et al. Accuracy of lymph node palpation to determine need for lymphadenectomy in gynecologic malignancies. Obstet Gynecol.2000; 95: 553-556.

12. Orr J, Chamberlain D: ACOG practice bulletin, clinical management guidelines for obstetriciangynecologists, no. 65, August 2005: Management of endometrial cancer. Obstet Gynecol 106:413, 2005.

13. Fleming GF, Brunetto VL, Cella D, et al: Phase III trial of doxorubicin plus cisplatin with or without paclitaxel plus filgrastim in advanced endometrial carcinoma: A Gynecologic Oncology Group study. J Clin Oncol 22: 2159, 2004 [PMID: 15169803].

\section{AUTHORS:}

1. Sabuj Baran Biswas

\section{PARTICULARS OF CONTRIBUTORS:}

1. Post graduate student, Department of Obstetrics and Gynaecology, S. C. B. Medical College, Cuttack.

FINANCIAL OR OTHER COMPETING INTERESTS: None
NAME ADDRESS EMAIL ID OF THE CORRESPONDING AUTHOR:

Dr. Sabuj Baran Biswas, C/o. Sunil Kumar Biswas, Deshbandhu Pally, P. O. + P. S., Naihati, District-24, Parganas (North)-743165, West Bengal.

E-mail: drsabuj23@gmail.com

Date of Submission: 11/07/2015. Date of Peer Review: 12/07/2015. Date of Acceptance: 27/07/2015. Date of Publishing: 03/08/2015. 